\title{
ENFERMEDAD DE JORGE LOBO O BLASTOMICOSIS QUELOIDIANA NUEVOS ASPECTOS DE LA ENTIDAD EN COLOMBIA. REVISION
}

\author{
GERZAIN RODRIGUEZ TORO*
}

La lobomicosis o enfermedad de Lobo la describió este autor en la Amazonia brasileña en 1931. El primer caso colombiano se informó en la Universidad del Valle en 1958. Se conocen más de 260 casos de esta entidad latinoamericana, 135 de los cuales han ocurrido en el Brasil y entre éstos, el $21 \%$ en la Tribu Caiabi. En Colombia se han informado nueve casos, pero en realidad son siete porque ha habido doble publicación de dos de ellos. Estos pacientes han sido mestizos o negros que consultaron a hospitales regionales o universitarios. En este trabajo presentamos diez casos de lobomicosis en indígenas Curripacos, Cubeos, Cuibas y Guahíbos, de Guainía, Vichada, Casanare y Vaupés, confirmados por biopsia cutánea enviada por médicos que prestan su Servicio Social Obligatorio en estas regiones. No se habían diagnosticado antes casos de epidemiología semejante entre nosotros.

\begin{abstract}
Revisamos además ocho pacientes remitidos por colegas o presentados en congresos nacionales de dermatología, con lo cual el número de colombianos con lobomicosis es de 25, la tercera frecuencia despúes del Brasil y de Surinam. La Orinoquia y la Amazonia en pacientes indígenas y la Costa Pacífica en la raza negra, son las áreas en las que predomina la lobomicosis. La complicación más frecuente es la ulceración que la hace confundir con leishmaniasis. En un indígena se desarrolló un carcinoma escamocelular sobre su lesión de lobomicosis, de dos años de evolución, que curó con la resección quirúrgica. Se ilustran aspectos macro y microscópicos de la entidad.
\end{abstract}

\section{DEFINICION}

Enfermedad crónica de la piel, caracterizada por nódulos y placas que corresponden a granulomas dérmicos en los cuales abunda el Paracoccidioides loboi, agente etiológico de la entidad.

\section{SINONIMIA}

Lobomicosis, blastomicosis queloidiforme, blastomicosis queloidea, granuloma blastomicoide, granuloma micótico de Lobo, falsa lepra, blastomicosis amazónica.

* Jefe del Grupo de Patología, Instituto Nacional de Salud. Apartado Aéreo 80334, Bogotá-Colombia Profesor Titular de Cátedra de los Departamentos de Patología y Morfología de la Facultad de Medicina de la Universidad Nacional. Bogotá - Colombia. 


\section{HISTORIA}

El primer paciente con esta entidad fue presentado en un congreso de la Sociedad Médica del Estado Pernambuco (Recife, Brasil) por el dermatólogo Jorge Lobo en 1931 (1). Se trataba de un hombre de 52 años, procedente del Estado de Amazonas, donde trabajaba como siringuero, que presentaba lesiones nodulares, levantadas, duras, queloidianas en la región sacra, que tenía 19 años de evolución. En el examen microscópico directo observó enorme número de microorganismos que interpretó como semejantes al $\boldsymbol{P}$. braziliensis y consideró que el paciente tenía una forma atenuada de paracoccidioidomicosis a la que llamó "blastomicosis queloidina".

En 1938, A. Fialho informó el segundo caso de la entidad en un hombre de 55 años, también residente en el Estado de Amazonas, que presentaba nódulos de 12 años de evolución en el pabellón auricular (2). Consideró que se trataba de una enfermedad distinta de la paracoccidioidomicosis y utilizó por primera vez el nombre de "Enfermedad de Lobo" para identificarla.

Los desarrollos subsiguientes se realcionan con el hongo productor de la enfermedad, organismo que originó muchas controversias y confusiones que aún hoy persisten (3-4), así como con los informes de otros países que mostraron que la entidad no se le limitaba sólo a la Hoya Amazónica (Fig. 1).

La entidad se ha descrito en Costa Rica (5), Panamá (6-7), Colombia (8-15), Guayana, Guayana Francesa, Venezuela, Surinam y Perú (16-19) (Tabla 1). Recientemente se describió también en México (20) y su carácter de micosis latinoamericana se amplió al demostrarse que los delfines de la Florida padecen lesiones cutáneas inducidas por un microorganismos semejante (21) (fig.1) (Tabla 1).

\section{ETIOLOGIA}

El hongo productor de la enfermedad es extraordinariamente abundante en las lesiones. El estudio de los pacientes produjo diferentes aislamientos y denominaciones para el microorganismo que ha sido objeto de controversias entre los micólogos $(3-4,16)$. Hoy se aceptan los siguientes criterios:

a. El organismo productor de la lobomicosis es enteramente distinto del $P$. braziliensis (4) aun cuando existen algunas reacciones inmunológicas cruzadas menores entre los dos microorganismos (14).

b. El P. loboi no se ha podido cultivar. Las cepas aisladas inicialmente representan contaminantes o confusiones de laboratorio (3-4).

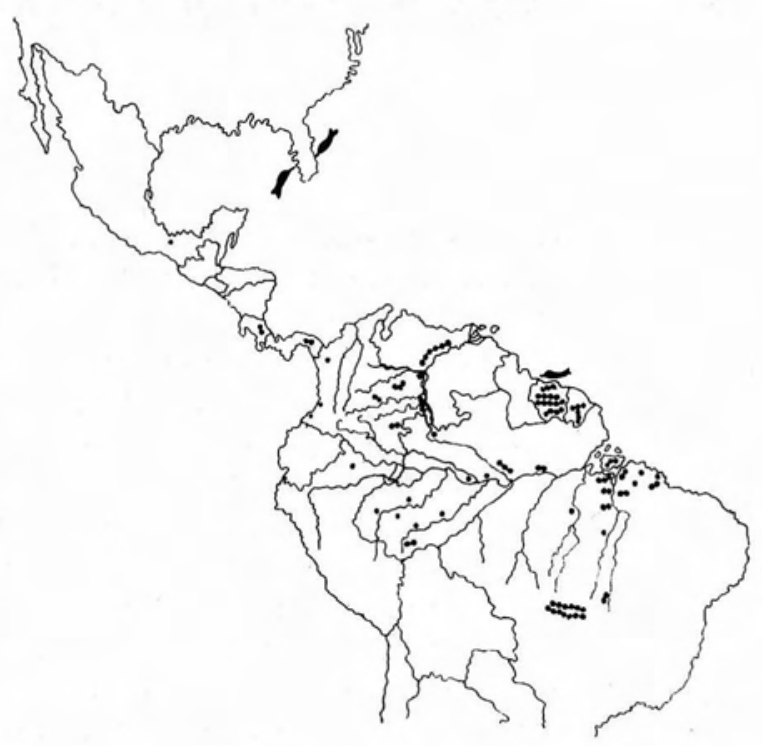

Fig. 1. Lobomicosis. Distribución geográfica. El número de puntos no se corresponde con el número de casos. La enfermedad en los delfines se presenta en Surinam y la Florida.

\section{TABLA 1}

\section{LOBOMICOSIS EN LATINOAMERICA}

\begin{tabular}{lc}
\hline & CASOS \\
BRASIL & 135 \\
SURINAM & 30 \\
COLOMBIA & 25 \\
PANAMA & 13 \\
VENEZUELA & 13 \\
GUYANAFR & 11 \\
COSTARICA & 4 \\
GUAYANA & 2 \\
MEXICO & 1 \\
PERU & 1 \\
\hline
\end{tabular}

Lo casos Colombianos han sido actualizados con los datos del presente trabajo. Los demás datos se basan en la referencia (18). 
c. El habitat del microorganismo no se conoce. La infección de los delfines y la enfermedad humana de áreas expuestas a trauma como el pabellón auricular, el grueso artejo y el dorso del pie, sugieren un origen acuático y en la vegetación de las áreas selváticas en las que predomina la entidad $(15$, 22-24).

d. Fuera de los delfines (Trusiops truncatus) no se conoce otro animal naturalmente infectado. La infección experimental se ha obtenido en hámsteres (4, 16-17), armadillos (21-23) y quelonios (23).

e. Un estudio exhaustivo de Fonseca y Lacaz (4), analizando las cepas aisladas de los primeros casos, concluye con las siguientes observaciones:

El nombre del agente de la lobomicosis debe ser:

Paracoccidioides loboi, (Fonseca \& Area Leao, 1940), Almeida \& Lacaz. 1949, con la sinominia de

Glenosporella loboi, Fonseca Filho y Area Leao, 1940

Glenosporopsis amazónica, Fonseca Filho, 1943.

Blastomyces loboi, Langeron \& Vanbreuseghen, 1952.

Loboa loboi, Ciferi, Azevedo, Campos \& Siqueira Carneiro, 1956.

y sus características:

"Hongo causal de la blastomicosis queloidiforme (enfermedad de Jorge Lobo), hasta hoy no comprobadamente cultivado, con enfermedad experimental no producida de manera sistemática, a no ser por pequeños nódulos en animales de sangre fría o en hámsteres dorados; presenta en su vida parasitaria riqueza de elementos predominantemente globoides (elípticos a ovoides), encadenados, que miden entre 6.0 - $13.5 \times 5.0-11.0$ micras con doble pared gruesa, se reproducen por gemación simple, sin esporulación. Las formas en rosario son frecuentes. La pared celular es gruesa, alcanzando una micra o más" (4).

\section{EPIDEMIOLOGIA}

La enfermedad humana ha sido descrita en diez países latinoamericanos (18) (Tabla 1) y en delfines, en la Florida y Surinam (21) (Fig. 1). Predomina en selvas densas, en climas calientes y húmedos, con ríos caudalosos y alta pluviosidad, entre los 1000 y $2500 \mathrm{~mm}$ anuales $(15,21-24)$.

La temperatura de las áreas endémicas varía entre 19 y $34^{\circ} \mathrm{C}$ con promedio de $27^{\circ} \mathrm{C}$. Los afectados son adultos jóvenes, hombres y mujeres de cualquier raza, siringueros, buscadores de oro y piedras preciosas, agricultores e indígenas $(16-17,21,23)$.

La enfermedad predomina en la Amazonia y es interesante que de los 267 casos descritos, cincuenta y siete $(21 \%)$ lo fueron en indígenas de la Tribu Caibai en el Brasil Central $(19,25)$, cuya población es hoy apenas de 300 miembros. Díaz y col. en 1970, sitúan 69 casos en la Amazonia brasileña (22). Entre 1973 y 1978 la micosis profunda más frecuente en Manaos fue la lobomicosis, con 22 casos (26).

La enfermedad se ha encontrado entre los 12 y los 85 años, con predominio alrededor de los 35 años. Los casos infantiles no tienen comprobación suficiente (19). Su duración se ha registrado hasta por 41 años, según el seguimiento practicado a los pacientes. En los grupos indígenas Caibai la edad de afección inicial estuvo entre los 2 y 25 años; la mujer se afectó en el $32 \%$, mientras que en otros grupos étnicos el compromiso femenino fue del 8\% (19). La afección del pabellón auricular, que en estudios iniciales llegó a ser del $40 \%$, se relacionó con la costumbre de cargar maderas y bultos al hombro, con traumatismo fácil del pabellón auricular. Esta situación no ocurre entre los Caibai (19).

\section{CLINICA}

No existe afección del estado general. Las lesiones cutáneas pueden comprometer cualquier parte del tegumento, respetando las mucosas. La entidad no afecta las vísceras y raras veces se ha observado adenopatía satélite, con demostración de levaduras en el ganglio linfático $(10,27)$. Las lesiones no son dolorosas y nunca curan espontáneamente; pueden ser únicas o múltiples, tienden a afectar una sola zona del cuerpo, propagándose por contigüidad, por la vía linfática o por autoinoculación $(17,19,27)$. 
Clínicamente se pueden observar lesiones diferentes según la evolución de la entidad; prodominan las pápulas, los nódulos y las placas infiltradas y verrucosas que a veces se ulceran, hecho que constituye la complicación más frecuente y molesta. El aspecto macroscópico queloideo de las placas y nódulos ha dado el nombre a la micosis. El tamaño de las lesiones varía de $1-30 \mathrm{~cm}$. El borde lesional es grueso y levantado, verrucoso y aunque se pueden ver cicatrices por curación de las úlceras, no hay tendencia a la cicatrización espontánea.

\section{PATOLOGIA}

La imagen microscópica de la lobomicosis es inconfundible (7-27). Muestra inflamación granulomatosa confinada a la dermis, con histiocitos espumosos, células gigantes, linfo y plasmocitos. No hay supuración, a excepción de los casos ulcerados. La fibrosis no es llamativa por lo cual el apelativo "queloide" no es siempre aplicable. Siempre resalta el enorme número de levaduras en cadenas o rosarios ramificados, unidas por puentes estrechos, con pared gruesa de 1 micra y tamaño general uniforme de 8-11 micras de diámetro. Se ven fagocitadas, intracelulares, en su mayoría, hecho que debería tenerse en cuenta para explicar la dificultad para cultivar el microorganismo. Las coloraciones de H.E, Grocott y PAS las demuestran muy bien, aunque la tinción con H.E. es irregular y puede demostrar el organismo central o sólo su cápsula, apareciendo el centro vacío. El epitelio que cubre la lesión es atrófico y está separado de los granulomas masivos dérmicos por una delgada banda de Una. No existe hiperplasia pseudoepiteliomatosa, excepto en los casos ulcerados. Excepcionalmente se ha visto esbozo de formación de hifas en los tejidos (22). Las células gigantes del infiltrado pueden contener cuerpos asteroides (16-17), que no tienen relación alguna con el cuerpo asteroide de la esporotricosis (28). Es llamativo el aspecto espumoso y voluminoso que toma el citoplasma de grupos de histiocitos, que semejan los de la enfermedad de Gaucher y que resultan, posiblemente, de la digestión del hongo o de su descomposición espontánea, con imposibilidad del macrófago para liberarse del mismo. Una biopsia pequeña con sacabocado que recaiga sobre esta zona puede originar confusión diagnóstica (17).

\section{INMUNOLOGIA}

El paciente desarrolla anticuerpos contra el hongo, que se demuestran con IF indirecta y que dan reacción cruzada débil con la paracoccidioidomicosis (14). Se ha ensayado una lobina; utilizando tejido de lesiones humanas $(19,27)$, de manera análoga a la reacción de Mitsuda, sin resultados útiles debido a la poca cantidad de material y de enfermos disponibles. Las lesiones no curan espontáneamente y no se visceralizan. A veces hay lesiones diseminadas (16-17) o profusas en pocos años pero la regla es que el hongo mantenga un equilibrio con el huésped, hecho que lo hace poco patógeno.

\section{DIAGNOSTICO}

La imagen clínica puede hacer sospechar la entidad por el aspecto queloideo o en placas de bordes verrucosos de las lesiones, o por su localización auricular en pacientes no indígenas. El frote directo revela enorme número de levaduras uniformes de pared gruesa. La histopatología es inconfundible. El diagnóstico diferencial se hace con la leishmaniasis, la cromomicosis, la lepra y diferentes tumores cutáneos.

\section{TRATAMIENTO}

Es básicamente quirúrgico. Las lesiones grandes, en placas, verrucosas y ulceradas pueden requerir varios procedimientos y siempre se debe juzgar si no es mejor para el paciente dejarlo convivir con sus lesiones que no amenazan su vida. Las recidivas son frecuentes. Los antimicóticos tradicionales y modernos no han dado resultados satisfactorios en los pocos casos en que se han ensayado $(12,18)$. El pronóstico es bueno, aunque la enfermedad es crónica.

\section{COMPLICACIONES}

La principal es la ulceración con infección secundaria. La recidiva luego de la escisión quirúrgica es frecuente. Dos indígenas Caibai presentaron carcinomas escamocelulares sobre su lobomicosis de 40 años de evolución. En un paciente se hizo amputación de un miembro y el otro falleció por metástasis pulmonares (25). 
12. LA ENFERMEDAD EN COLOMBIA (Tablas 1-4) (Figs. 1-14).

El primer caso de la enfermedad de Lobo en Colombia fue publicado por J. Betancourt Osorio y E. Correa Galindo (8), prioridad que también reclama P. Correa (9). El análisis de ambas publicaciones revela tantas coincidencias que nos ha hecho deducir que se trata del mismo caso. El enfermo del trabajo de F. Londoño (12) fue incluído entre los dos casos publicados por Peña (13). En conclusión, los casos de lobomicosis publicados de Colombia, entre 1958 y 1982, son siete (8-15, Tabla 2). Estos fueron enfermos de raza negra o mestiza que acudieron a los hospitales consultando por la enfermedad. Un vuelco epidemiológico importante se empezó a dar a partir de 1982, cuando los casos diagnosticados han aumentado y se ven en indígenas de la Amazonia y de la Orinoquia (Tabla 3 ). Los factores que han permitido este hecho son, entre otros, el desplazamiento de médicos, odontólogos, enfermeras y bacteriológas, hacia estas zonas para realizar su año de servicio social obligatorio. Este desplazamiento se ve favorecido por los mejores salarios ofrecidos en estos territorios por las Seccionales de Salud y porque los cupos para años rurales en localidades cercanas a las grandes ciudades son cada

TABLA 2

LOBOMICOSIS EN COLOMBIA 1958-1982

\begin{tabular}{|c|c|c|c|c|c|c|c|c|}
\hline \multicolumn{2}{|c|}{ No. Raza } & \multirow{2}{*}{\begin{tabular}{|l} 
Edad \\
25
\end{tabular}} & \multirow{2}{*}{$\begin{array}{l}\text { Sexo } \\
M\end{array}$} & \multicolumn{2}{|c|}{ Evolución Procedencia } & \multirow{2}{*}{$\begin{array}{l}\text { Sitio y No. de } \\
\text { lesiones }\end{array}$} & \multirow{2}{*}{$\begin{array}{l}\text { Profesión } \\
\text { Minero }\end{array}$} & \multirow{2}{*}{$\begin{array}{l}\text { Referencia } \\
\text { Betancourt \& } \\
\text { Correa, } 1958\end{array}$} \\
\hline $1^{*}$ & Negra & & & $1.5 \mathrm{~A}$ & - & & & \\
\hline $2^{*}$ & Negra & 33 & $M$ & $2.5 \mathrm{~A}$ & Timba (Cáuca) & $\begin{array}{l}\text { Pie y pierna izquierda } \\
\text { múltiples nódulos }\end{array}$ & Minero & Correa, 1958 \\
\hline 3 & Mestiza & 46 & $M$ & $1 \mathrm{~A}$ & Chocó & Pie, varios nódulos & Minero & Robledo, 1964 \\
\hline 4 & Negra & 47 & $\mathrm{~F}$ & $5 \mathrm{~A}$ & $\begin{array}{l}\text { Cajambre } \\
\text { (Cáuca) }\end{array}$ & $\begin{array}{l}\text { Pie, pierna izquierda } \\
\text { múltiples nódulos }\end{array}$ & - & $\begin{array}{l}\text { Martínez \& } \\
\text { Hoffman, } 1965\end{array}$ \\
\hline $5^{* *}$ & Mestiza & 38 & $M$ & $25 \mathrm{~A}$ & $\begin{array}{l}\text { Orocué } \\
\text { (Casanare) }\end{array}$ & $\begin{array}{l}\text { Pie y pierna derecha } \\
\text { múltiples nódulos }\end{array}$ & Agricultor & Londoño, 1968 \\
\hline $6^{* *}$ & Mestiza & 38 & $M$ & $25 \mathrm{~A}$ & Boyacá & $\begin{array}{l}\text { Pie y pierna derecha } \\
\text { múltiples nódulos }\end{array}$ & Agricultor & Peña, 1967 \\
\hline 7 & $?$ & 25 & $\mathrm{M}$ & - & $\begin{array}{l}\text { Ocaña } \\
\text { (Norte de S.) }\end{array}$ & $\begin{array}{l}\text { Codo izquierdo } \\
\text { nódulo unico }\end{array}$ & Albañil & Peña, 1967 \\
\hline 8 & Mulato & 38 & $\mathrm{~F}$ & $3 A$ & $\begin{array}{l}\text { Dabeiba } \\
\text { (Antioquia) }\end{array}$ & $\begin{array}{l}\text { Antebrazo izquierdo } \\
\text { nódulo único }\end{array}$ & Hogar & $\begin{array}{l}\text { Jaramillo et al } \\
1976\end{array}$ \\
\hline 9 & Mestiza & 30 & $\mathrm{M}$ & $4 \mathrm{~A}$ & $\begin{array}{l}\text { Saravena } \\
\text { (Arauca) }\end{array}$ & $\begin{array}{l}\text { Pie y pierna derecha } \\
\text { nódulos múltiples }\end{array}$ & Agricultor & $\begin{array}{l}\text { Mogollón, } \\
1982\end{array}$ \\
\hline
\end{tabular}

* Informes del mismo caso.

**Informes del mismo caso. 
TABLA 3

LOBOMICOSIS EN INDIGENAS DE LA AMAZONIA Y LA ORINOQUIA. COLOMBIA, 1982-1987

\begin{tabular}{|c|c|c|c|c|c|c|}
\hline No. & Tribu & $\begin{array}{l}\text { Edady } \\
\text { Sexo }\end{array}$ & $\begin{array}{l}\text { Evolu- } \\
\text { ción }\end{array}$ & Procedencia & Sitio y número de lesiones & DX. Clínico \\
\hline 1 & Curripaco & $51 \mathrm{M}$ & $22 \mathrm{~A}$ & Morroco (Guainía) & $\begin{array}{l}\text { Tumor ulcerovegetante, } \\
\text { hombro derecho }\end{array}$ & Ca. escamocelular \\
\hline 2 & Curripaco & $50 \mathrm{M}$ & $10 \mathrm{~A}$ & Cejal (Guainía) & Nódulo queloideo escapular & Lipoma \\
\hline 3 & Curripaco & $50 \mathrm{~F}$ & $15 \mathrm{~A}$ & Cejal (Guainía) & $\begin{array}{l}\text { Varios nódulos y placas en } \\
\text { antebrazo izquierdo }\end{array}$ & Cromicosis \\
\hline 4 & Curripaco & $50 \mathrm{~F}$ & $5 \mathrm{~A}$ & Muerciélago (Guainía) & $\begin{array}{l}\text { Dos nódulos ulcerados de } \\
\text { labio inferior }\end{array}$ & Ca. escamocelular \\
\hline 5 & Cubeo & $70 \mathrm{M}$ & $40 \mathrm{~A}$ & Tapurucuara (Vaupés) & $\begin{array}{l}\text { Más de } 20 \text { nódulos } \\
\text { en abdomen }\end{array}$ & Lobomicosis \\
\hline 6 & Cubeo & $60 \mathrm{M}$ & $5 \mathrm{~A}$ & Campoalegre (Vaupés) & $\begin{array}{l}\text { Nódulos y placas en } \\
\text { brazo y antebrazo izquierdo }\end{array}$ & Lepra metástasis \\
\hline 7 & Cuiba & $50 \mathrm{M}$ & $2 \mathrm{~A}$ & $\begin{array}{l}\text { San José de Ariporo } \\
\text { (Casanare) }\end{array}$ & $\begin{array}{l}\text { Nódulo ulcerado, pierna } \\
\text { izquierda }\end{array}$ & Leishmaniasis \\
\hline 8 & Cuiba & $35 \mathrm{M}$ & $5 \mathrm{~A}$ & $\begin{array}{l}\text { San José de Ariporo } \\
\text { (casanare) }\end{array}$ & $\begin{array}{l}\text { Dos nódulos en brazo } \\
\text { izquierdo }\end{array}$ & Leishmaniasis \\
\hline 9 & Guahibo & $28 \mathrm{~F}$ & $2 A$ & $\begin{array}{l}\text { Caño Negro, Cazuarito } \\
\text { Rio Orinoco (Vichada) }\end{array}$ & $\begin{array}{l}\text { Ulcera, cara externa } \\
\text { rodilla derecha }\end{array}$ & Leishmaniasis \\
\hline 10 & Cuiba & $45 \mathrm{M}$ & $2 \mathrm{~A}$ & Yopal (Casanare) & $\begin{array}{l}\text { Más de } 20 \text { nódulos en pie y } \\
\text { pierna izquierda }\end{array}$ & $\begin{array}{l}\text { Lepromas, } \\
\text { Xantomas }\end{array}$ \\
\hline
\end{tabular}

vez más escasos y competidos entre los 1.400 médicos que anualmente se gradúan en el país. También, los servicios hospitalarios de estas áreas han mejorado, existen grupos de trabajo, hay supervisión universitaria y toda la Orinoquia y Amazonia ofrecen una naturaleza paradisíaca que difícilmente podrán visitar posteriormente. Las comunidades indígeneas de estas zonas han podido disfrutar de mejor atención médica, que incluye la búsqueda activa de casos mediante largos desplazamientos por transporte aéreo y fluvial.
El Grupo de Patología del Instituto Nacional de Salud ha tratado de prestar ayuda eficiente y oportuna a estos grupos médicos mediante el análisis de las muestras que periódicamente nos envían. Así se ha duplicado prácticamente el diagnóstico de la enfermedad de Lobo y muy importante, se muestra su frecuencia en comunidades indígenas como los Curripacos, Guahibos, Cuibas y Cubeos (Tabla 3). Con este servicio se ha demostrado también una frecuencia relativamente alta de pénfigo foliáceo (fogo selvagem) y de 
hiperplasia epitelial focal oral entre el mismo grupo de tribus.

El análisis de la tabla 3 permite enfatizar la cronicidad de la afección que se registra hasta por 40 años. Tiende a ser una enfermedad acral, con lesiones múltiples, en placas o en nódulos de los cuales un paciente tiene más de 20 en el abdomen. Cuatro indígenas tuvieron ulceración de las lesiones lo que se considera una complicación importante de la entidad. En un paciente la úlcera correspondió histológicamente a un carcinoma escamocelular infiltrante, bien diferenciado, de tipo verrucoso, cunicular, en cuyas invaginaciones llenas de queratina colonizó otro hongo de hifas septadas, posiblemente un dermatofito, distinto del $P$. loboi que abundaba en la periferia del tumor y entre el infiltrado inflamatorio del carcinoma (Figs. 7-11). En todos los casos el diagnóstico se hizo por histopatología.

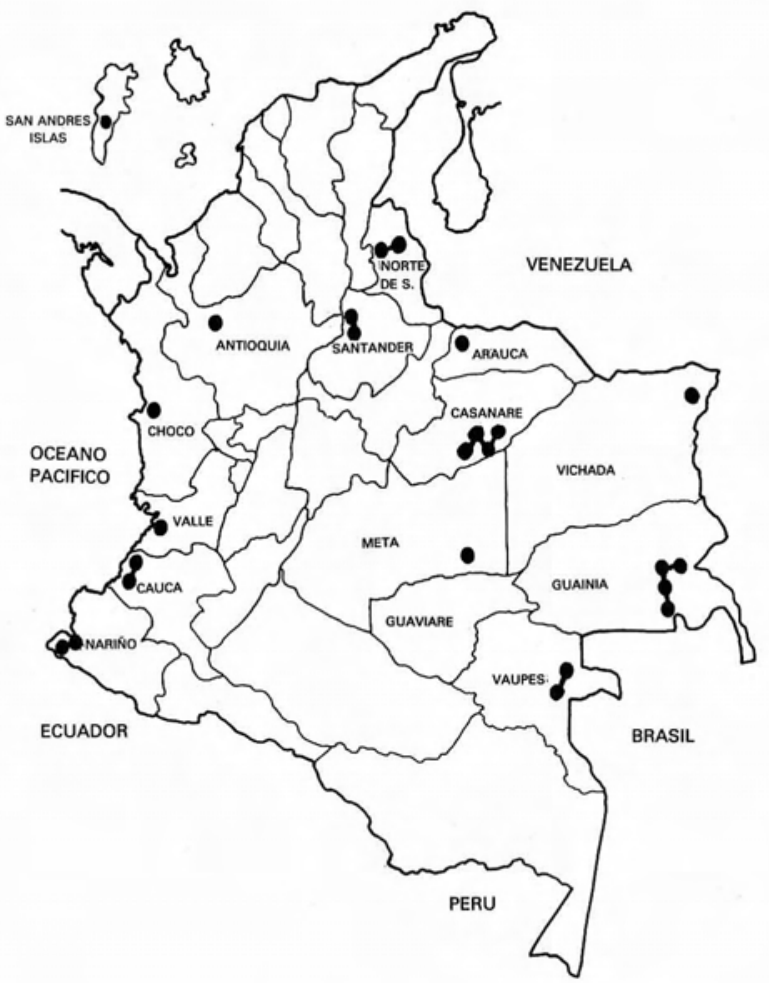

fig. 2. Distribución de los casos de lobomicosis en Colombia.
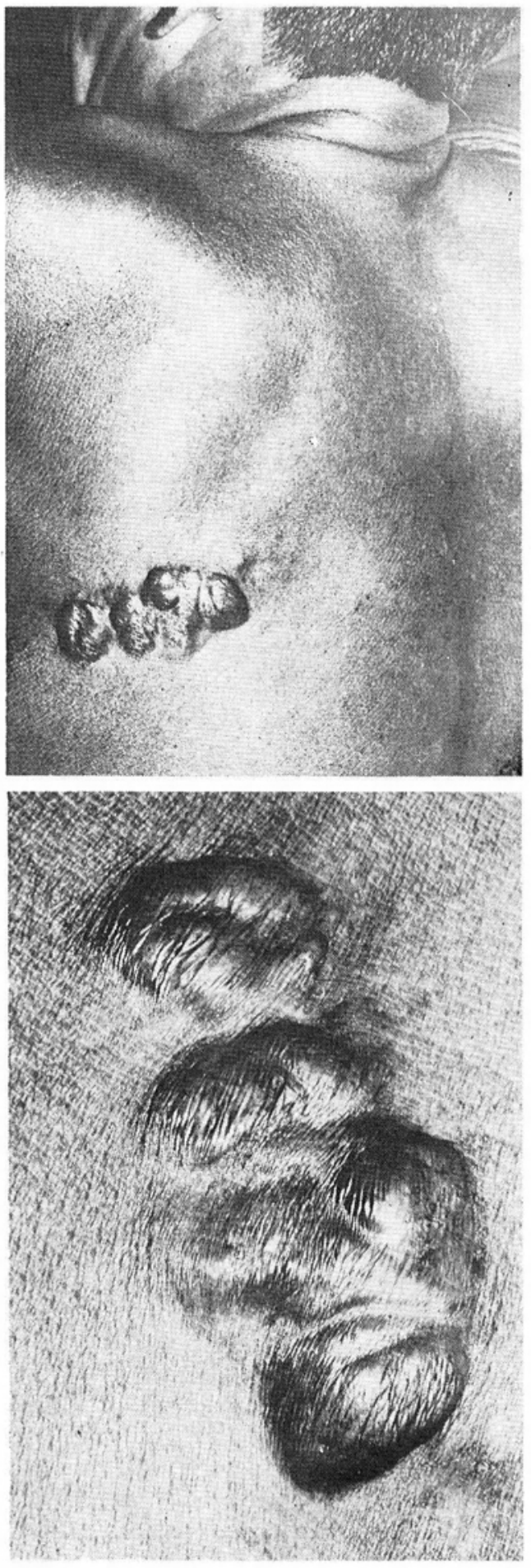

Figs. 3 y 4 . Placa queloidea en un indígena Curripaco del Cejal (Guainia). A pesar de extirpación amplia, actualmente hay pequeños nódulos de recidiva. 
Sabemos, además, de la existencia de otros pacientes que han sido presentados en congresos nacionales, o cuyos especímenes nos han sido gentilmente remitidos por colegas (Tabla 4) y entre los cuales es de resaltar la ulceración en dos de ellos y que tres correponden a pacientes de raza negra de la Costa Pacífica.
La importancia de conocer esta entidad se demuestra con el hallazgo de un paciente en la isla de San Andrés, con un nódulo queloideo recidivante en el pabellón auricular izquierdo. El nódulo se estirpó y se envío a Cartagena para estudio histológico que confirmó la lobomicosis (Tabla 4).

TABLA 4

\section{LOBOMICOSIS EN COLOMBIA 1984-1989. CASOS ADICIONALES}

\begin{tabular}{|c|c|c|c|c|c|c|c|}
\hline No. & Raza & Edad & Sexo & Evolución & Procedencia & Lesiones & DX Histológico \\
\hline 1 & Negra & 45 & M & $6 \mathrm{~A}$ & Tumaco (N) & Varios nódulos lumbares & Dr. AZeballos (Popayán) \\
\hline 2 & Negra & 42 & M & $3 \mathrm{~A}$ & Tumaco (N) & $\begin{array}{l}\text { Placas en mano y brazo } \\
\text { derecho }\end{array}$ & Cideim. Dr. Giraldo (Cali) \\
\hline 3 & Negra & 80 & M & $2 A$ & $\begin{array}{l}\text { Buenaventura } \\
\text { (V) }\end{array}$ & $\begin{array}{l}\text { Placa y nódulo ulcerado, } \\
\text { pierna derecha }\end{array}$ & $\begin{array}{l}\text { Dra. D. Pulido } \\
\text { (Buenaventura) }\end{array}$ \\
\hline $4^{*}$ & Mestizo & 29 & M & $1 \mathrm{~A}$ & Casanare & $\begin{array}{l}\text { Nódulo de antebrazo } \\
\text { derecho }\end{array}$ & Dr. L. A. Rueda (Bogotá) \\
\hline $5^{*}$ & Mestizo & 35 & M & $2 \mathrm{~A}$ & Santander & $\begin{array}{l}\text { Dos nódulos en brazoy } \\
\text { antebrazo }\end{array}$ & $\begin{array}{l}\text { Drs. L.C. Orozco y K. } \\
\text { Zamora (Bucaramanga) }\end{array}$ \\
\hline $6^{*}$ & Blanca & 71 & M & $10 \mathrm{~A}$ & Santander & $\begin{array}{l}\text { Placa en codo y brazo } \\
\text { derecho }\end{array}$ & $\begin{array}{l}\text { Dr. K. Zamora } \\
\text { (Bucaramanga) }\end{array}$ \\
\hline 7 & Mestizo & 58 & M & $5 \mathrm{~A}$ & $\begin{array}{l}\text { Cúcuta (Norte } \\
\text { de Santander }\end{array}$ & Placa ulcerada en la nuca & $\begin{array}{l}\text { Instituto Nacional de Salud } \\
\text { (Bogotá) }\end{array}$ \\
\hline 8 & Mestizo & 34 & M & $5 \mathrm{~A}$ & $\begin{array}{l}\text { San Andrés } \\
\text { Isla }\end{array}$ & $\begin{array}{l}\text { Nódulo queloide recidi- } \\
\text { vante en oreja izquierda }\end{array}$ & $\begin{array}{l}\text { Dr. J.M. Caraballo } \\
\text { (Cartagena) }\end{array}$ \\
\hline
\end{tabular}

*Casos presentados en el XV Congreso Colombiano de Dermatología, Bucaramanga, octubre 31 a noviembre 4 de 1984. 


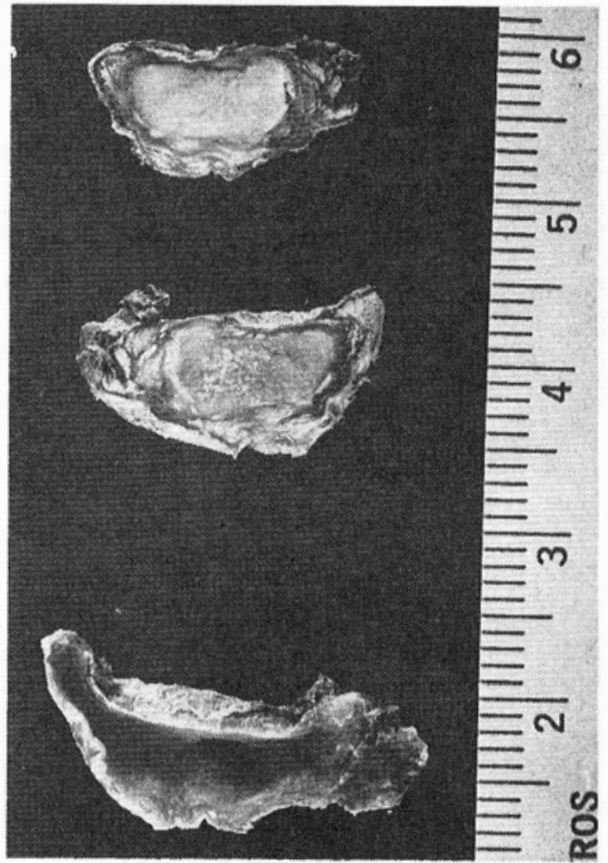

4

Fig. 5. Nódulo queloideo, completamente extirpado de un indígena de San José de Ariporo.

Fig. 6. Nódulo ulcerado del antebrazo en un paciente no indígena de Santander $y$ pequeño nódulo satélite en el brazo.
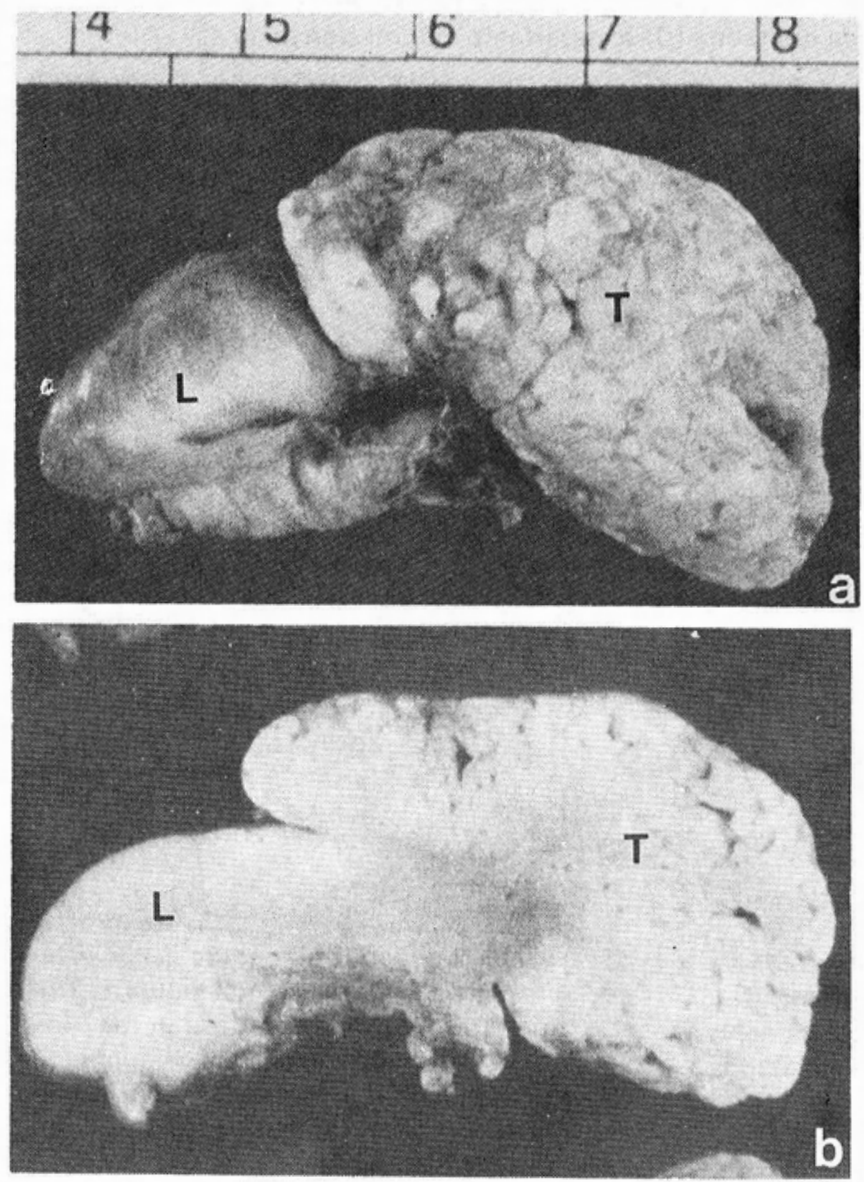

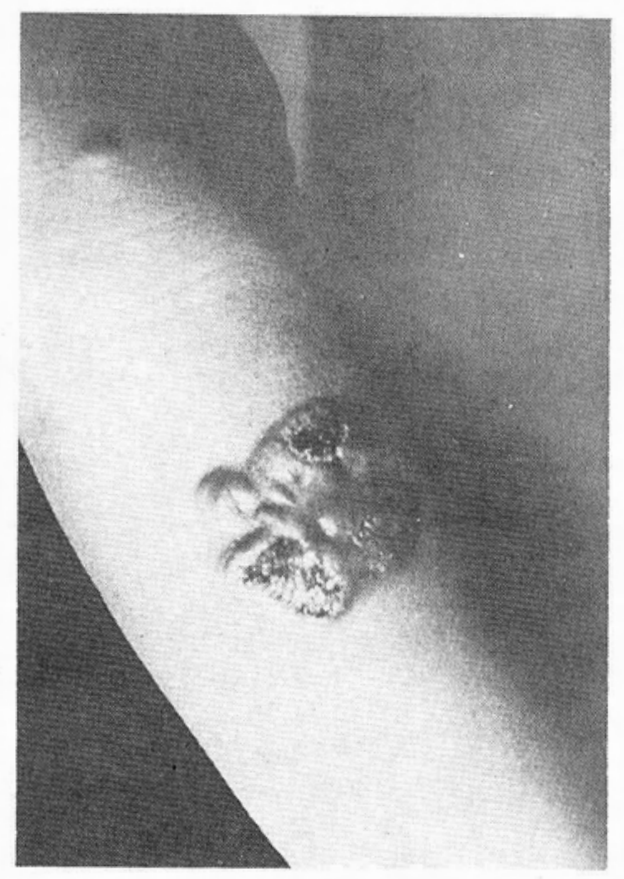

Fig. 7a. y 7b. Nódulo de aspecto tumoral en el hombro de un indígenea Curripaco, visto exteriormente (a) y al corte (b); la parte más voluminosa y nodular $(T)$ correspondió a un carcinoma escamocelular cunicular, con infección doble, por un dermatofito y por $P$. loboi. La parte homogénea, menos protruyente ( $L$ ) es un granuloma dérmico masivo repleto de $P$. loboi. (Véanse Figuras 8-11). Escala en $\mathrm{cm}$, igual para ambas fotografías. 

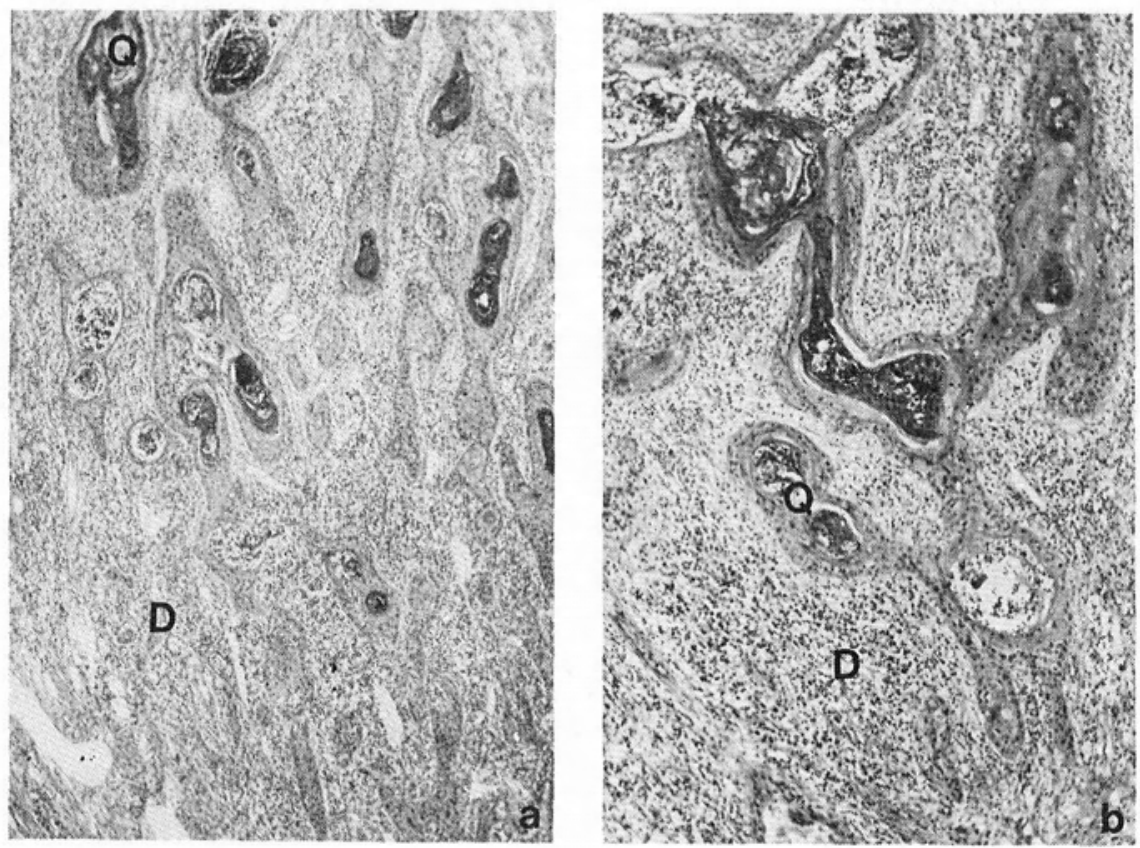

Fig. 8a. y 8b. Aspecto atípico, tumoral, infiltrante de la lesión marcada $T$ en las figuras anteriores, con invaginaciones llenas de queratina (Q) e importante inflamación en la dermis (D). HE. $63 \mathrm{X}$.

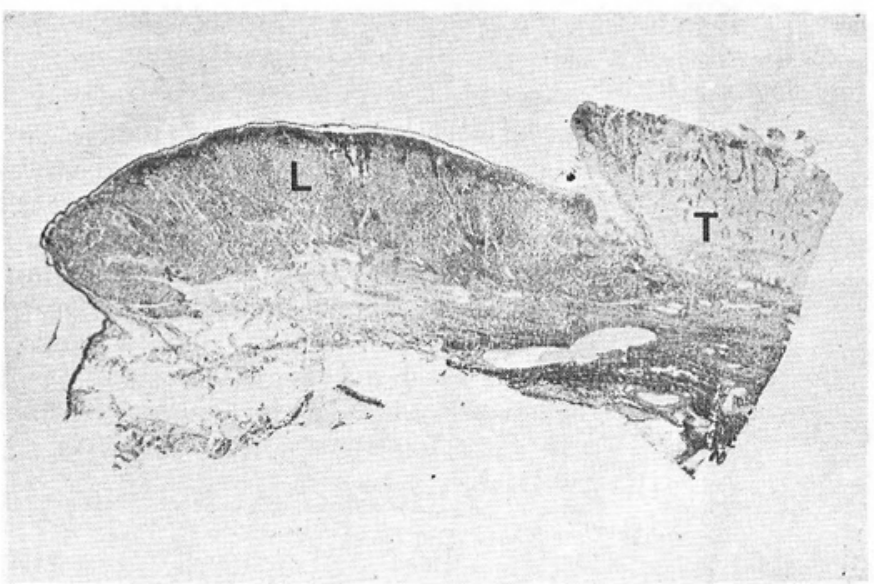

Fig. 9. Imagen panorámica de parte de la lesión demostrada en la Figura 7. Fotografía tomada con lupa. L: área de lobomicosis. $\mathrm{T}$ : área del carcinoma cunicular. La mayor parte del color negro, más notorio en la zona $L$, corresponde a $P$. loboi fagocitados por macrófagos. Tinción de Grocott.

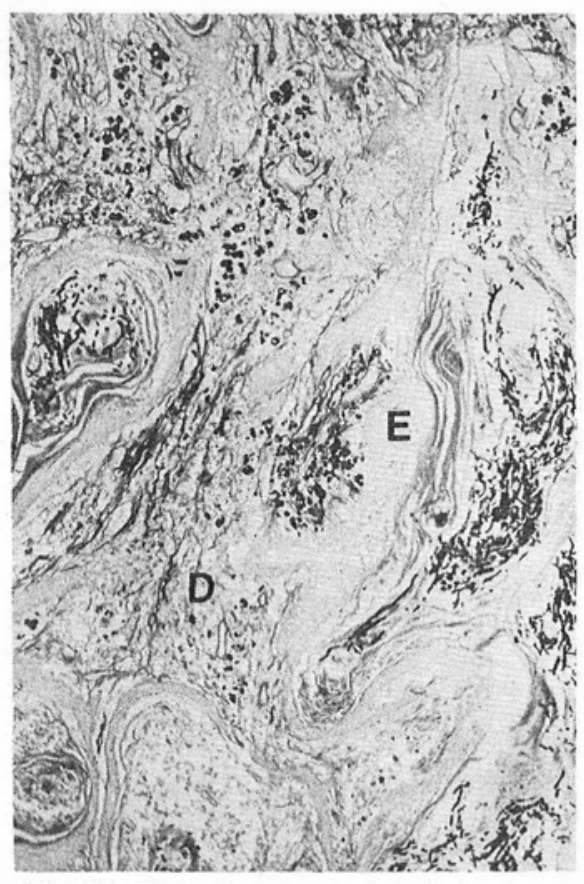

Fig. 10. Pequeños aumentos de las invaginaciones tumorales de la Figura 8. Tinción de Grocort. Se demuestran micelios en las invaginaciones llenas de queratina y $P$. loboi en el infiltrado dérmico (D). EI epitelio tumoral $(E)$ separa los dos compartimientos. $63 \mathrm{X}$. 

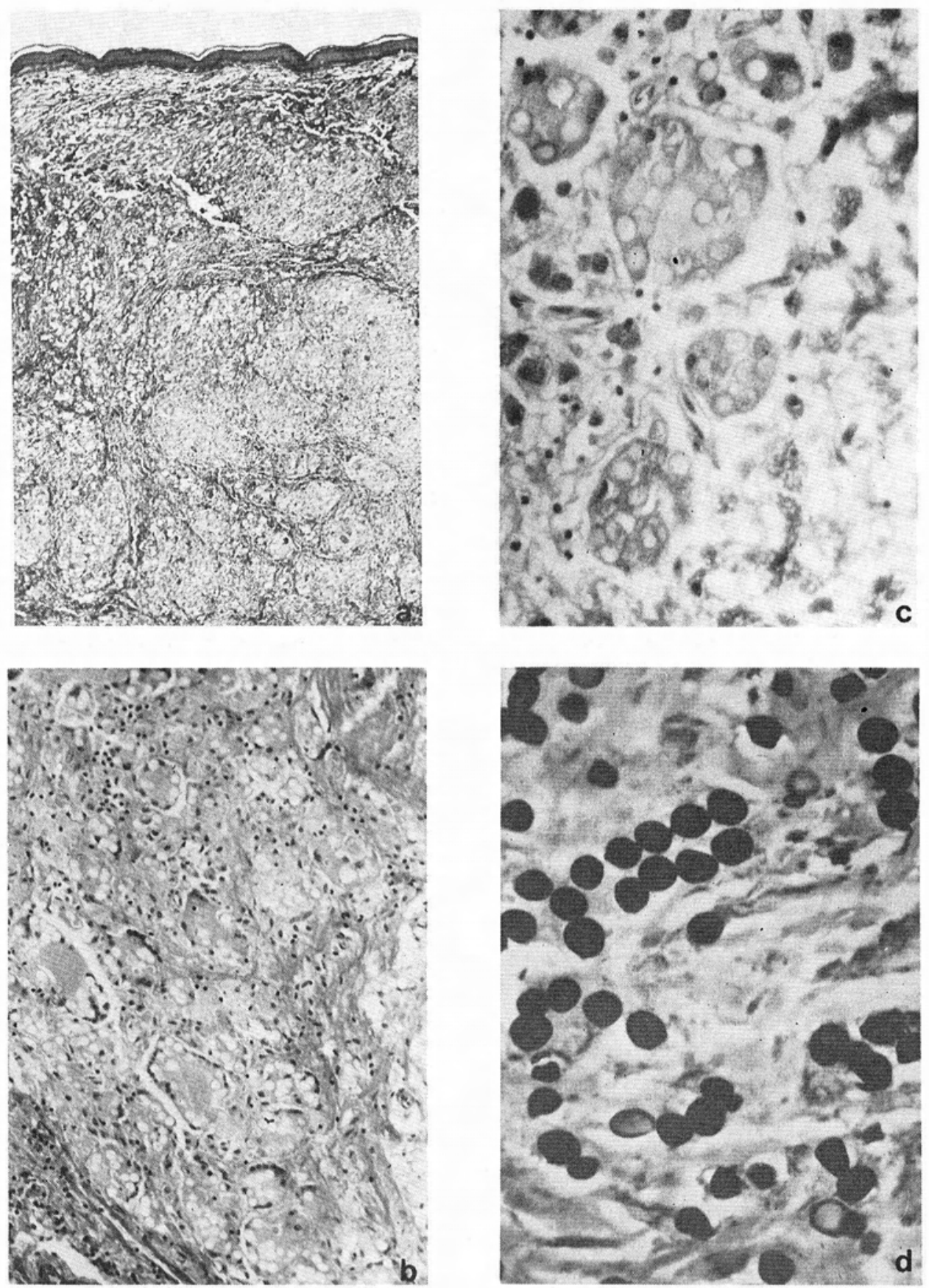

Fig. 11. Imágenes del área (L) de las figuras ariteriores; se ve inflamación granulomatosa con células gigantes y muy abundantes $P$. loboi fagocitados en cadenas. a: Tricrómico $160 \mathrm{X} ; \mathrm{b}: \mathrm{y}$ c: HE 160 X. d: Grocott 400 X. 

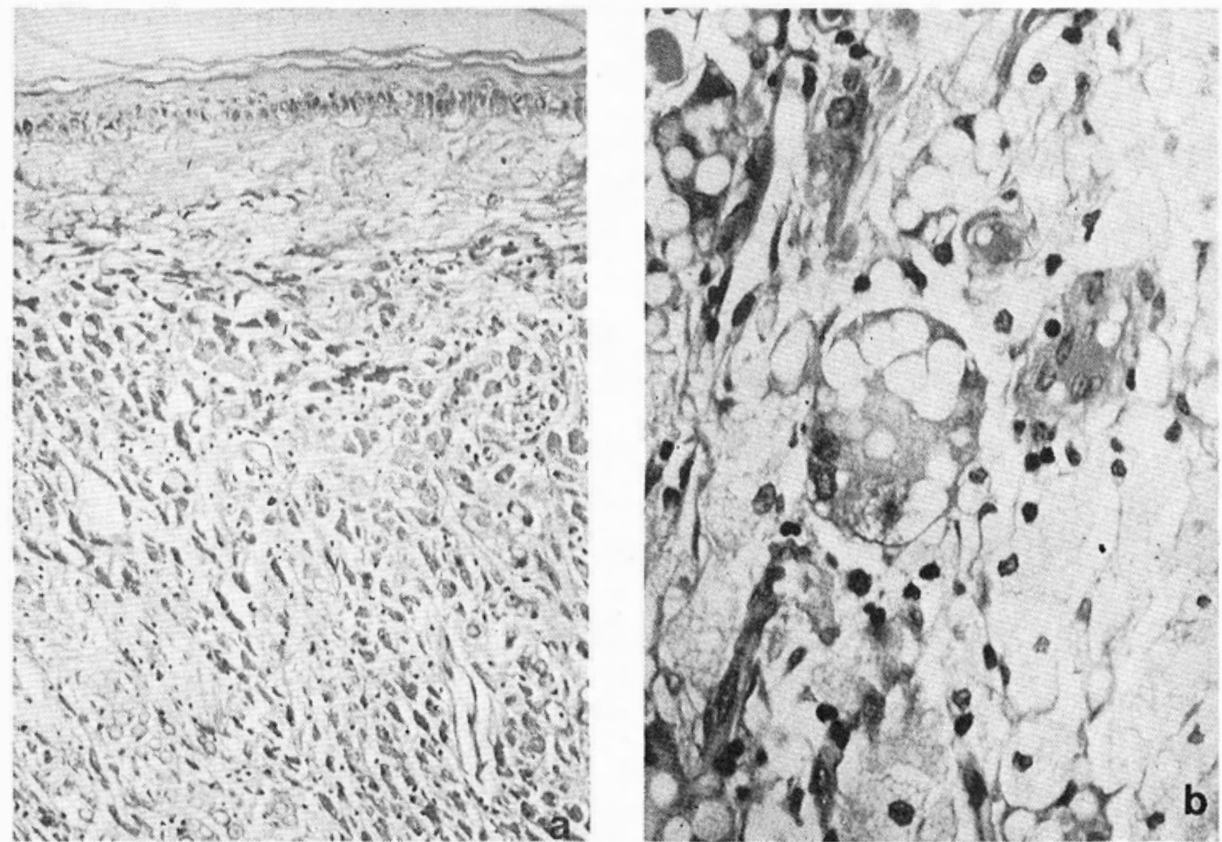

Fig. 12a. y 12b. Histiocitos espumosos grandes, repletos de material citoplasmático PAS positivo. P. loboi en la profundidad. En la Figura $12 \mathrm{~b}$ se ve la transición de histiocitos llenos de hongos a los "tesaurismósicos". La célula gigante en (b) contiene un cuerpo asteroide. a: PAS 160, b: HE. $400 \mathrm{X}$.

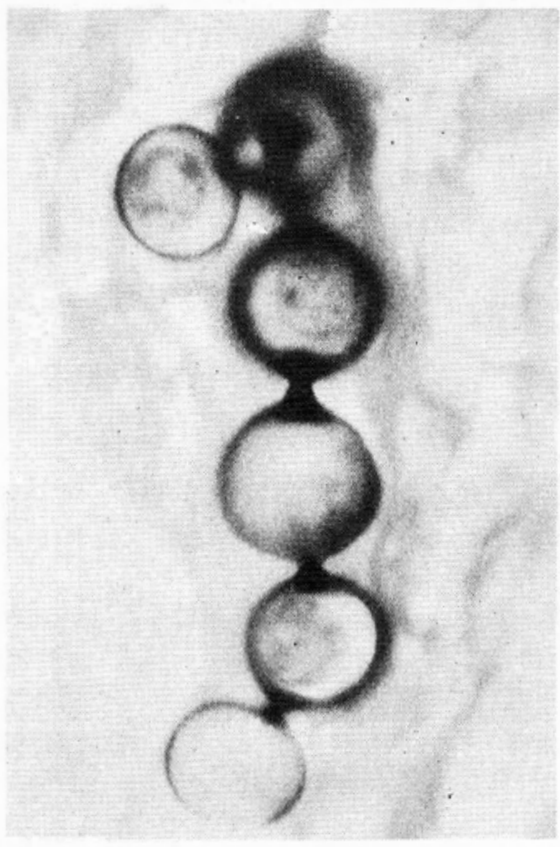

Fig. 13. Típicas cadenas de $P$. Ioboi en un paciente indígena del Vaupés. Resaltan muy bien los puentes de unión entre las levaduras, que tienden a ser de tamaño uniforme. Grocott 1000 X.

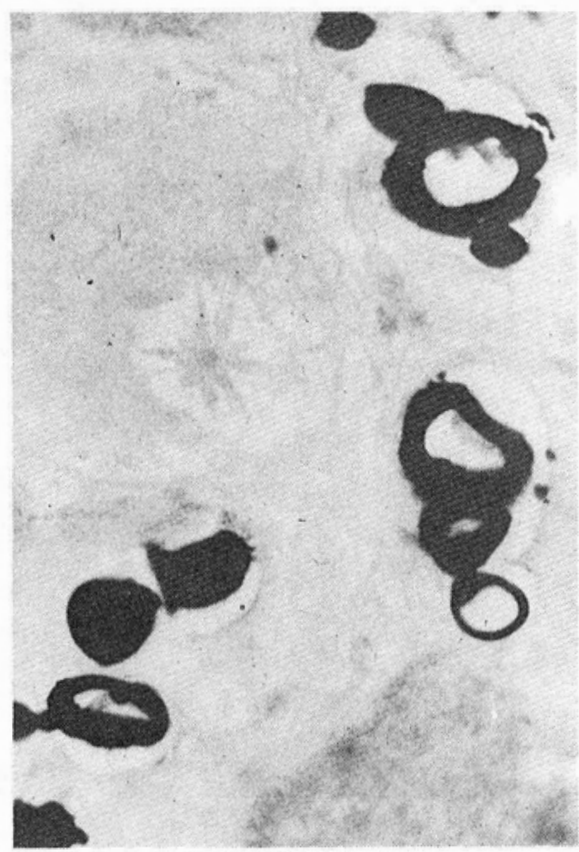

Fig. 14. Cuerpo asteroide en una célula gigante del granuloma. Se ven $P$. lobo fagocitados en células vecinas. Grocott $1000 \mathrm{X}$. 


\section{CONCLUSION}

El análisis de los casos publicados y de los aquí reunidos permite concluir que el número de pacientes colombianos con lobomicosis es por lo menos de 25 , lo cual coloca a nuestro país en el tercer lugar de frecuencia, después del Brasil y de Surinam. (Tabla 1). Diez de éstos pacientes son indígenas de la Amazonia y de la Orinoquia y 6 son de raza negra de la Costa Pacífica, lo cual sugiere la existencia de dos biotopos colombianos selváticos o semiselváticos, húmedos y lluviosos, propicios para el desarrollo de lobomicosis. La enfermedad de Lobo no se había informado antes entre indígeneas colombianos.

\section{SUMMARY}

Lobo's disease is a subcutaneous mycosis which was first described by Jorge Lobo in 1931 in a patient fron the Brazilian Amazon region. The first colombian case was reported in Cali (Universidad del Valle) in 1958.

Lobo's disease in humans is unique to Latin-America. Over 260 cases of this disease have been reported, 135 from Brazil, $21 \%$ of which have occurred among the Cayabi indian tribe.

Until 1982, only nine colombian cases had been reported. Two of these were published twice, signifying that the acutal number of cases are seven. These were either mestizo or negro patients who attended teaching on local hospitals.

In this paper we report ten cases of Lobomycosis is Amer Indians patients (Curripaco, Cubeo, Cuiba and Guahibo tribes), from Guainía, Vichada, Casanare and Vaupés regions. Their disgnosis was confirmed by skin biopsies sent to the National Institute of Health in Bogotá by physicians serving a compulsory year of social service. There are no previous reportes of this disease among colombian Amer-Indian communities.

We also reviewed eigth patients either referred to us by colleagues or presented at the XIV National Congress of Dermatology, in 1984. Thus, the current number of reported cases of Lobomycosis in Colombia has risen to 2.5 , making it the third highest frequency in the world behind Brazil and Surinam. The geographical regions where this disease is prevalent in Colombia are the Orinoco and Amazon rivers basins, where Amer-Indians patients are affected, and the Pacific Coast, where the black patients come from.

Lobomycotic lesions are plaques and nodules of chronic evolution, which occur predominantely in male patients. Lobomycosis, most common complication is ulceration, making leishmaniasis the most important differential diagnosis. One Amer-Indian patient developed a squamous cell carcinoma over a Lobomycotic lesion with two-years of evolution. This patient was completely cured after surgical excision of the lesion.

A general review of Lobomycosis is made and macro and microscopic features are illustrated.

\section{AGRADECIMIENTO Y RECONOCIMIENTO}

A los médicos, enfermeras, bacteriólogas, odontólogos, auxiliares y administradores que trabajan o han trabajado en los Servicios de Salud del Vichada, Guainía, Vaupés y Casanare, cuya devoción por sus pacientes nos ha permitido estudiar las biopsias de los mismos. Agradecemos especialmente a los doctores Josué Carvajal, Alvaro Santich M. (quien informó sobre un caso de Lobomicosis en el "Boletín Epidemiológico del Vichada”, Año 1. Volumen 2, 1983), Orlando Calderón y Gustavo Moreno (por suministrarnos datos y material de los casos de San José de Ariporo), Oscar Leonel Ramírez R, Clara Patricia Santamaría, Carlos T. Mejía, Ernesto Ojeda, Juan Carlos Pacheco, Alvaro Silva, José A. Morales y Adriana Ballesteros.

Al laboratorio de Micología del INS por facilitarnos las Figuras 3 y 4.

Al doctor Luis Carlos Orozco por facilitarnos la Figura 6.

A la bióloga Leonor Caldas por su ayuda en la elaboración de los mapas de las Figuras 1 y 2. 


\section{BIBLIOGRAFIA}

1. Lobo J.Um caso de blastomicose produzido por uma especie nova encontrada em Recife. Rev Med Pernambucana, 1931; 1 : 763-775.

2. Fialho A. Blastomicose du tipo "Jorge Lobo". O Hospital, 1938; 14: 903.

3. Borelli D. Lobomicosis: Nomenclatura de su agente. Medic Cut, 1968; 3 (2): 152-156.

4. Fonseca OJ de M, Lacaz C da S. Estudo de culturas isoladas de blastomicosis queloidiforme (doenca de Jorge Lobo). Denominacao ao seu agente etiologico. Rev Inst Med Trop Sao Paulo, 1971; 13: 225-251.

5. Trejos A, Romero A. Contribución al estudio de la blastomicosis en Costa Rica. Rev Med Trop 1953; 1: 63-81.

6. Herrera JM. Paracoccidioidosis brasiliense. Estudio del primer caso observado en Panamá de blastomicosis suramericana en su forma cutánea queloidiana o enfermedad de Lobo y propuesta de una variante técnica para la impregnación argéntica del parásito. Arch Med Panam. 1955; 4: 209-219.

7. Tapia A, Torres Calcindo A, Arosemena R. Keloidal blastomicosis (Lobo,s disease) in Panama. Int J Dermatol, 1978; $17: 572-574$.

8. Betancourt OJ, Correa GE. Blastomicosis queloidiana o enfermedad de Jorge Lobo. Arch Arg Derm 1958; 8 (3): 231-232.

9. Correa P. Blastomicosis queloidea. Rev latinoam Anat Patol. 1958; 2: 139-143.

10. Martínez FA, Hoffman E. Blastomicosis queloidiana. Ant Med 1965; 15 (6): 417-425.

11. Robledo VM. Enfermedad de Jorge Lobo (Blastomicosis queloidiana). Presentación de un nuevo caso colombiano. Mycopathol Mycol Appl. 1967; 33: 313-320.

12. Londoño F. Blastomicosis queloidiana. A propósito de un caso tratado con Anfotericina B. Med Cut. 1968; 2 (5): $521-524$.

13. Peña CE. Blastomicosis queloide en Colombia. Presentación de dos casos Mycopath Mycol Appl. 1967; 33: 313320 .

14. Jaramillo D, Cortés A, Restrepo A, Builes M, Robledo M. Lobomycosis. Report of the eight Colombian case and review of the literature. J Cut Pathol 1976; 3: 180-189.
15. Mogollón TJ. Lobomicosis. Presentación de un caso y revisión de la literatura colombiana. Mycopathologie. 1982; 80: 65-72.

16. Wiersema JP, Niemel PLA. Lobo's disease in Surinam patient. Trop Geogr Med 1965; 17: 80-111.

17. Wiersema JP. Lobo's disease (keloidal blastomycosis) In the Pathologic Anatomy of Mycoses. Human infections with Fungi. Actinomycetes and Algae. Edit Baker RN 1971; pp. 577-588, Springer-Verlag. Berlin.

18. Lawrence D, Ajello L. Lobomycosis in western Brazil: Report of a clinical trial with Ketoconazole. Am J Trop Med Hyg 1986; 35 (1): 162-166.

19. Varuzzi RG. Lacaz C de S, Souza, PAA. Historia Natural da doenca de Jorge Lobo. Ocurrencia entre os indios Caibai (Brasil Central). Rev Med Trop Sao Paulo. 1979; 21 (6): 302-338

20. Zavala-Velásquez J, Reyes Pérez A. Enfermedad de Lobo (Lobomicosis). Primer caso mexicano. Demato (Mex), 1978; 22 (1): 5-12.

21. Caldwell DK, Cadwell MC, Woodard JC, Ajello L, Ka plan W, McClure HM. Lobomycosis as a disease of the Atlantic bottle-nosed dophin (Tursiops truncatus Montagu, 1821). Am J Trop Med Hyg, 1975; 24 (1): 105-114.

22. Dias BL, Sampaio MM, Silva D. Jorge Lobo's disease Observations on its epidemiology and some unusual morphological forms of the fungus. Rev Inst Med Trop Sao Paulo, 1970; 12: 8-15.

23. Sampaio MM, Braga-Dias L. The armadillo Euphractus Sexinctus as a suitable animal for experimental studies of Jorge Lobo's disease. Rev Inst Med Trop Sao Paulo $1977 ; 19$ (4): 215-220

24. Borelli D. La reservarea de la lobomicosis. Mycopathol Mycol Appl 1969; 37: 145-149.

25. Baruzzi RG, Rodríguez DA, Michalany NS, Salomao R. Squamous-cell carcinoma and lobomycosis (Jorge Lobo's disease). Int J Dermatol, 1989; 28: 183-185.

26. Talhari S, Gadelha AR, Cunha MGS, Fernandes G, Paes MA. Micosis profundas na Amazonia. Estudo dos casos diagnosticados en Manaus, Estado de Amazonas, no periodo de 1973 a 1978. an Bras Derm 1980, 55 : 133-136.

27. Azulay RD, Carnerio JA, Cunha DGS, et al. Keloidal blastomycosis (Lobo's disease) with lymphatic involvement. Int J Dermatol. 1976; 15: 40-42.

28. Rodríguez G. El cuerpo asteroide de la esporotricosis Especificidad y diferenciación de otras formas asteroides. Biomédica 1985; 5 (1-2): 11-23. 


\section{COMENTARIOS BIBLIOGRAFICOS}

\section{MAS GRANDES QUE EL AMOR}

\author{
Dominique Lapierre
}

Planeta. Seix - Barral-Barcelona 1990.

En 1982 Biomédica 2:205 hizo una excepción en su sección de comentarios bibliográficos dedicada a obras científicas biomédicas, para comentar el libro "ANATOMIA DE UNA EPIDEMIA" de los periódistas Gordon Tomas y Max Morgan-Witts. Hoy volvemos a interrumpir nuestro reglamento para comentar otra obra que sin ser científica tiene un interés histórico de la mayor trascendencia. En 1982 decíamos que posiblemente nunca volvería a vivir la medicina un momento como el que se vivió con la aparición de la enfermedad de los Legionarios. Que lejos estábamos de imaginar que ya caminaba sobre el mundo el mayor desafío para la salud pública que la medicina ha vivido y que el SIDA se constituiría en el desafío sin precedente. Su autor, Dominique Lapierre, pasea al lector por páginas apasionantes de Calcuta a Jerusalén pasando por San Francisco, Los Angeles, Nueva York, Atlanta, Bethesda metiendo al lector prácticamente en la historia de cada uno de los protagonistas, viviendo con ellos sus tragedias, sus frustraciones, sus asombros, sus triunfos; en ocasiones no se entiende como se pasa de las salas de muerte de Calcuta a los saunas de Nueva York; no sabe el lector como llegará a tener un punto común de enlace aquel acontecer en apariencia inconexo; y el punto surge al final, teriendo como centro el SIDA: agonizante Josef Stein vencido y lacerado por la enfermedad, pero rodeado por el afecto de sus amigos, de otros pacientes y la protección y cariño de las Hermanas Misioneras de Agnes Bojaxhiu, Sor Teresa de Calcuta, ese ser ecepcional cuya existencia nos reconcilia con el género humano; en esa escena patética, Stein exala su última expresión sobre la tierra justedes son más grandes que el amor! frase que Lapierre toma para titular su obra magistral. Como períodismo de investigación la obra no tiene par; como documento histórico se debe agradecer a Lapierre este trabajo, porque reconstituir paso a paso la historia del surgimiento del SIDA describiendo con absoluta precisión todos y cada uno de los problemas que fue necesario vencer hasta aclarar todos los aspectos de ésta gran tragedia biológica, es tarea de una enorme complejidad. Lapierre es preciso en describir los aspectos estrictamente técnicos y científicos; en todo este relato no hay sino una sola imprecisión técnica, cuando dos de las hermanas misioneras de Calcuta son mordidas por un perro rabioso se inicia la angustiosa búsqueda de "un suero" cuando en realidad se trata de una vacuna que no se consigue inexplicablemente en ninguna parte de Calcuta; cuando al fin llega, de algún otro lugar, llega tarde para una de las hermanas que muere poco después de Rabia.

Este libro debe estar en la biblioteca de todo médico, de todo investigador, de todo epidemiólogo, aquí se precisan algunos hechos oscuros que rodearon el aislamiento del retrovirus causal del SIDA y surge sin duda el grupo de Luc Montagnier como el grupo que logró esa hazaña. El tiempo ha hecho justicia a este grupo. Más grande que el amor es un gran documento histórico. 


\section{BIOMEDICA}

INSTITUTO NACIONAL DE SALUD

Volumen 9, Nos. 1 y $2 ; 3$ y 4 de 1989

\section{INDICE DE AUTORES}

Agudelo Carlos, Nos. 3 y 4, pág. 117.

Andrade Eugenio, Nos. 3 y 4, pág. 83.

Boshell Jorge, Nos. 3 y 4, pág. 99.

Bueno Martha Lucía, Nos. 1 y 2, pág. 13.

Cáceres Vega Elvia, Nos. 3 y 4, pág. 117.

Cardona Libia, Nos. 3 y 4.83.

Castañeda Elizabeth, Nos. 1 y 2, págs. 26 y 30 .

Castillo Jannette, Nos. 1 y 2, pág. 30.

De La Hoz Fernando Pío, Nos. 3 y 4, págs. 93 y 99.

Guzmán Urrego Miguel, Nos. 3 y 4, pág. 147.

Heredia Reinaldo, Nos. 1 y 2, pág. 23.

Hernández Laura, Nos. 3 y 4, pág. 93.

Hurtado Hugo, Nos. 3 y 4, pág. 105.

Juliao R. Oscar, Nos. 3 y 4, pág 109.

Márquez Gladys, Nos. 3 y 4, págs. 93 y 99.

Martínez D. Máncel, Nos. 3 y 4, págs. 93 y 99

Mejía Luz, Nos. 3 y 4, pág. 117.

Moncada Ligia, Nos. 3 y 4, pág. 117.

Morales Alberto, Nos. 1 y 2. pág. 13.

Moreno Martha Lucia, Nos. 3 y 4, pág. 75.

Mosquera Ruth, Nos. 1 y 2, pág. 5

Naranjo Patricia de, Nos. 1 y 2, pág. 32.

Ordoñez Nelly, Nos. 1 y 2, pág. 26.

Parra Fonseca José, Nos. 3 y 4, pag. 93 y 99.

Ricaurte Orlando, Nos. 1 y 2, págs. 32 y 58.

Rivas M. Fabio, Nos. 3 y 4, pág. 93 y 99.

Rodríguez Toro Gerzaín, Nos. 1 y 2, págs. 32, 58 y 64. Nos. 3 y 4, págs. 120 y 133.

Rodríguez Leonardo, Nos. 3 y 4, pág. 105.

Saad Acosta Cecilia, Nos. 3 y 4, págs. 93 y 99.

Urrea Luis Leonardo, Nos. 3 y 4, pág. 75.

Vargas Clara Inés de Nos. 1 y 2, pág. 23.

Vergara Claudia, Nos. 3 y 4, pág. 83.

Vernot Jean Paul Nos. 1 y 2, pág. 5

Wasserman Moisés, Nos. 1 y 2, pág. 5. Nos. 3 y 4, pag. 75. 


\section{BIOMEDICA}

INSTITUTO NACIONAL DE SALUD

Volumen 9, Nos. 1 y $2 ; 3$ y 4 de 1989

\section{INDICE DE ARTICULOS}

Blastomicosis queloidiana. Enfermedad de Jorge Lobo o Blastomicosis queloidiana. Nuevos aspectos de la entidad en Colombia. Revisión. Nos. 3 y 4, pág. 133.

Comentarios Bibliográficos. Nos. 3 y 4, pág. 147.

Chlamydia trachomatis. Infección por Chlamydia trachomatis. Cándida albicans y Neisseia Gonorrhoeae en mujeres embarazadas. Nos. 1 y 2, pág. 23.

Dengue Hemorrágico . Dengue Hemorrágico en Colombia. Aspectos clínicos, enero-junio/90. Nos. 3 y 4 , pág. 93.

Dengue, Vigilancia Intensificada sobre el dengue y los primeros casos de Dengue Hemórragico confirmados en Colombia durante el 10. semestre de 1990. Nos. 3 y 4, pág. 99.

Enfermedad de Heck. Hiperplasia epitelial focal de la boca en Colombia. Enfermedad de Heck. Nos. 3 y 4 , pág. 120.

Esporotricosis. Esporotricosis diagnósticada por el laboratorio. Nos. 1 y 2, pág. 26.

Hígado. Granulomas infecciosos del hígado. Nos. 1 y 2, pág. 32.

Hipertensión. Hipertensión arterial en Colombia. Nos 3 y 4, pág. 109.

Lepra. La biopsia de piel en lepra. Nos 1 y 2, pág. 64.

Micobacterium leprae. Antígenos solubles Micobacterium leprae y PPD en escolares de la Isla de Pascua y Santiago de Chile, 1987. Nos. 3 y 4, pág. 105.

Paracoccidioides brasiliensis. Determinación de anticuerpos contra $P$. brasiliensis e $H$. capsulatum en una población de mamíferos silvestres. Nos. 1 y 2, pág. 30.

Plasmodium falciparum. Análisis cualitativo y cuantitativo de la respuesta inmune-humoral a $P$. falciparum en personas protegidas y no protegidas. Nos. 3 y 4 , pág. 75.

Plasmodium falciparum. Comparación de diferentes sondas de DNA para detección de $P$. falciparum. Nos. 3 y 4 , pág. 83.

Proechimys sp. Caracterización cariológica de Proechimys sp. (Rodentia echimyidae) de una colonia esperimental. No. 1 y 2, pág. 13.

SIDA. La leucoplasia viral lingual del SIDA. Nos. 1 y 2, pág. 58

Síndrome diarreico. Cryptosporidium y Blastomicosis hominis como agentes patógenos en el síndrome diarreico. Nos. 3 y 4, pág. 117.

Síntesis de espectrina. Inducción de la diferenciación en células eritroleucémicas humanas y murinas: Síntesis de espectrina. Nos. 1 y 2, pág. 5. 


\section{INSTRUCCIONES PARA LOS AUTORES}

1. BIOMEDICA, la revista del Instituto Nacional de Salud, recibirá para publicación únicamente artículos originales e inéditos. Se exceptúan de esta norma los trabajos de Investigadores Científicos del Instituto que hayan sido publicados en revistas científicas extranjeras de reconocida prestancia internacional.

2. La revista aceptará artículos, fruto de la investigación que contribuyan a ampliar los conocimientos sobre biomedicina, realizados tanto en el Instituto Nacional de Salud como en cualquier otro centro científico de investigación.

Los artículos deberán llenar los siguientes requisitos:

a) Ser enviados al editor de la revista, Apartados 80080 y 80334 , zona 6, Bogotá, D. E., Colombia S.A.

b) Ser escritos a máquina, en papel blanco, original y una copia, tamaño carta, doble espacio, dejando márgenes de $4 \mathrm{cms}$. a la izquierda y $2 \mathrm{cms}$. a la derecha.

c) Los resúmenes deben ser escritos en español, con traducción al inglés (en hojas separadas).

d) Tener un título conciso, si fuere necesario, un subtítulo.

e) Llevar los nombres del autor o los autores inmediatamente después, indicando con asteriscos, en el pie de página, su título académico y la institución en la cual se realizó el trabajo.

f) El trabajo debe incluir: Introducción, Materiales y Métodos, Resultados, Discusión, Conclusiones y Referencias Bibliográficas.

g) Las citas bibliográficas se harán en el texto en forma consecutiva, utilizando números arábigos y deberán aparecer, en el mismo orden numérico de citación. La referencia se presenta así: apellido del autor, seguido de las iniciales de su nombre, título del artículo, nombre abreviado de la revista, año de publicación, volumen, número y página. Ejemplo: Barrow $\mathrm{CH}$. Cryptococcosis in animals. JAMA. 1955; 127: 125.

Para la citación de libros se seguirá un orden similar, así: Pearse A., Texbook of Biochemistry. Saunders Edt., 1979; pp 49.

h) Los cuadros, gráficas y figuras deben numerarse en forma consecutiva con números arábigos y ser presentados en papel fotográfico brillante, en blanco y negro, manteniendo individualmente la proporción para una columna, dos columnas o página entera. Dicho material debe ser de calidad y presentación impecables, con su correspondiente leyenda.

3. La revista también aceptará para publicación: actualizaciones, memorando, revisiones, comunicaciones breves, cartas al editor, revisión de resúmenes e informes técnicos.

4. Todo material propuesto para publicación será revisado por el Comité Editorial. El Editor informará a los autores, sobre la recepción de los trabajos, y sobre la decisión final que se tome.

5. La revista se reservará el derecho de aceptar o rechazar los artículos y podrá hacer sugerencias que tiendan a mejorar su presentación. Para un mejor cumplimiento de esta función el Comité Editorial consultará a especialistas en la materia.

6. Los originales de los artículos publicados permanecerán en los archivos de la revista; aquellos no aceptados, serán devueltos a sus autores.

7. El autor principal recibirá libre de costo 5 ejemplares de la revista y 100 separatas de su trabajo. 